\title{
A novel C202F mutation in the connexin 26 gene (GFB2) associated with autosomal dominant isolated hearing loss
}

Laurette Morlé, Muriel Bozon, Nicole Alloisio, Philippe Latour, Antoon Vandenberghe, Henri Plauchu, Lionel Collet, Patrick Edery, Jacqueline Godet, Geneviève Lina-Granade

\begin{abstract}
Mutations in the $G J B 2$ gene encoding connexin26 (CX26) account for up to $50 \%$ of cases of autosomal recessive hearing loss. In contrast, only one $G J B 2$ mutation has been reported to date in an autosomal dominant form of isolated prelingual hearing loss. We report here a novel heterozygous $605 \mathrm{G} \rightarrow T$ mutation in GJB2 in all affected members of a large family with late childhood onset of autosomal dominant isolated hearing loss. The resulting C202F substitution, which lies in the fourth (M4) transmembrane domain of CX26, may impair connexin oligomerisation. Finally, our study suggests that GJB2 should be screened for heterozygous mutations in patients with autosomal dominant isolated hearing impairment, whatever the severity of the disease. (F Med Genet 2000;37:368-370)
\end{abstract}

Keywords: C202F mutation; connexin26 gene (GfB2); autosomal dominant hearing loss

Neurogénétique Moléculaire, Hôpital de l'Antiquaille, 69321 Lyon Cédex 05, France P Latour

A Vandenberghe

Service de Génétique, Hospices Civils de Lyon, Hôpital Hôtel-Dieu, 69288 Lyon Cédex 02, France $\mathrm{H}$ Plauchu P Edery

Laboratoire Neurosciences et Systèmes Sensoriels, UPRESA CNRS 5020 Hôpital Edouard Herriot, 69347 Lyon Cédex 03, France L Collet

G Lina-Granade

Correspondence to: Dr Morlé,

1-morle@univ-lyon1.fr

Revised version received 15 October 1999 Accepted for publication 18 October 1999 1). In this family, hearing loss was deter between 10 and 20 years of age in most of the affected persons. We found intrafamilial vari- ability for the severity of hearing loss, which was restricted to high frequencies during the first decade and progressed to middle frequencies between 10 and 50 years of age.

We performed genetic linkage analysis in this family using a set of microsatellite markers linked to dominant DFNA1-15 loci and recessive DFNB1-17 loci. ${ }^{11}$ We obtained significant positive lod scores of 3.88 at $\theta=0$ and 3.27 at $\theta=0$ with D13S175 and D13S141 microsatellite markers, respectively. Since these two markers are closely linked to GfB2, we screened the whole $G \mathcal{F B} 2$ coding sequence for mutations in our patients. Single strand conformation polymorphism (SSCP) analysis of the GFB2 coding sequence showed an abnormal pattern in affected subjects. Direct sequencing showed a heterozygous $G \rightarrow T$ mutation at nucleotide 605, resulting in a cysteine to phenylalanine substitution at codon 202 (C202F, fig 2A). The remaining coding sequence showed no SSCP anomaly. The $605 \mathrm{G} \rightarrow \mathrm{T}$ mutation resulted in the loss of an $S f a \mathrm{NI}$ site. Restriction site analysis using $S f a \mathrm{NI}$ showed heterozygosity for the $605 \mathrm{G} \rightarrow \mathrm{T}$ mutation in all affected family members (fig $2 B$ ). In contrast, this mutation was absent in healthy family members and in 95 controls.

CX26 belongs to a large family of proteins which form intercellular channels and allow rapid exchange of small molecules between adjacent cells. ${ }^{12}{ }^{13} \mathrm{CX} 26$ is also thought to play an important part in auditory transduction, by recycling endolymphatic potassium ions. In the rat and mouse cochlea, CX26 is highly expressed in the supporting cells of the sensory epithelium and in the fibrocytes lining the cochlear duct. ${ }^{214}{ }^{15}$ Several lines of evidence suggest that the $\mathrm{C} 202 \mathrm{~F}$ mutation reported here may play an important role in CX26 function. Firstly, the C202F mutation affects an amino acid which is invariable among 17 vertebrate connexins. ${ }^{16}$ This mutation lies in the fourth (M4) transmembrane domain of CX26, which seems to be important for protein folding. ${ }^{17}$ In addition, a heterozygous mutation (C201R) affecting the CX32 analogous cysteine underlies severe $\mathrm{X}$ linked Charcot-Marie-Tooth disease. ${ }^{18}$ Moreover, a truncation mutation, thought to result in the deletion of the M4 


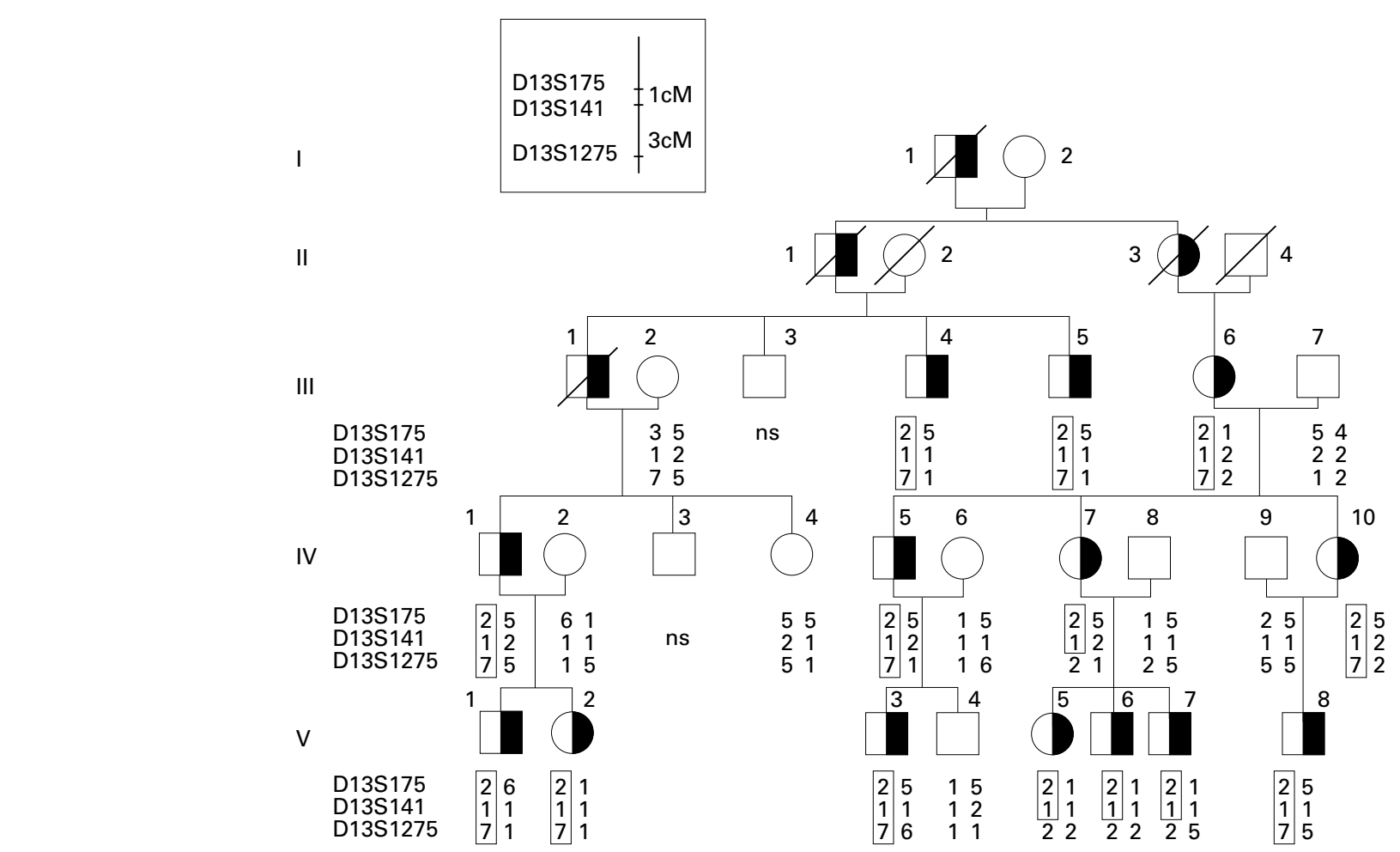

Control

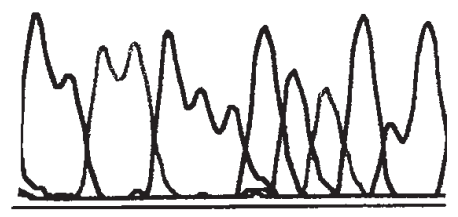

G G A A T T T N A T C C

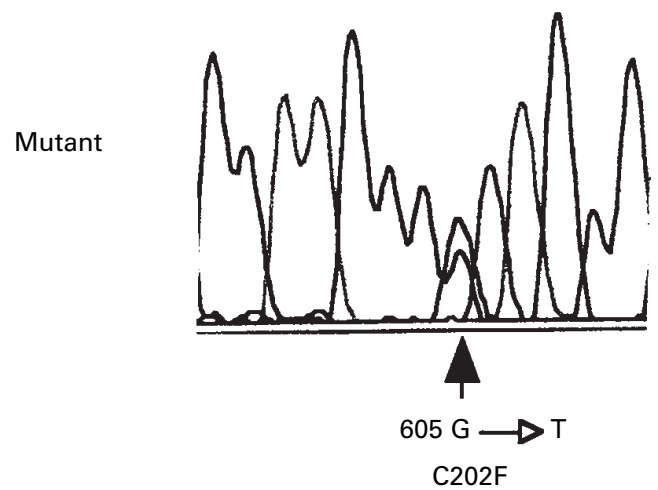

B

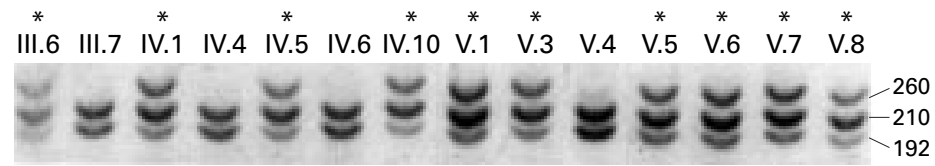

Figure 2 (A) DNA sequence showing the $605 G \rightarrow T$ GFB2 mutation in an affected subject. (B) SfaNI restriction site analysis of PCR amplified DNA from family members. The $260 \mathrm{bp}$ fragment corresponds to the mutant allele. Affected members are indicated by an asterisk. domain of CX31, is associated with dominant, late onset hearing loss. ${ }^{16}$ As six CX26 molecules oligomerise to form a hemichannel or connexon, ${ }^{17}$ the $\mathrm{C} 202 \mathrm{~F}$ mutation might disturb the interaction between the M4 domain of one mutant CX26 and the M2 domain of the neighbouring connexin, thus resulting in the formation of a non-functional channel.

Heterozygous GFB2 mutations have previously been found in families with palmoplantar keratoderma and sensorineural hearing loss, ${ }^{1920}$ and in dominant non-syndromic deafness in only one instance. ${ }^{8}$ This latter heterozygous GFB2 mutation (W44C), which is associated with profound prelingual and progressive non-syndromic deafness, lies in the E1 extracellular loop of the protein involved in interactions between connexons of adjacent cells. $^{8}$ In contrast, the heterozygous C202F GFB2 mutation reported here in late onset hearing impairment lies in the M4 transmembrane domain of the protein, thought to be important for connexin oligomerisation.

Finally, our observation suggests that screening for mutations in $G \mathcal{F B}$ 2, which account for up to $50 \%$ of autosomal recessive hearing loss cases, should also be performed in autosomal dominant hearing loss cases, even in late onset forms of the disease.

We thank the family members, Dr Hamon, Dr Malard, Dr Salomon, and Dr Simon for their cooperation, and Dr Bey-Cabet and Professor Morel for providing control DNA samples. We also thank Mrs Therre for her technical help. This work was supported by the Centre National de la Recherche Scientifique (UMR 5534), the Université Claude Bernard Lyon I, and the Hospices Civils de Lyon. 1 Van Camp G, Willems PJ, Smith RJH. Nonsyndromic hear-
ing impairment: unparalleled heterogeneity. Am f Hum
Genet 1997;60:758-64. 
2 Kalatzis V, Petit C. The fundamental and medical impacts of recent progress in research on hereditary hearing loss. of recent progress in research on

3 Van Camp G, Smith RJH. Hereditary hearing loss homepage. World Wide Web URL: http://dnalabwww.uia.ac.be/dnalab/hhh/, September, 1999.

4 Denoyelle F, Weil D, Maw MA, et al. Prelingual deafness: high prevalence of a 30 delG mutation in the connexin 26 gene. Hum Mol Genet 1997;6:2173-7.

5 Estivill X, Fortina P, Surrey S, et al. Connexin-26 mutations in sporadic and inherited sensorineural deafness. Lancet 1998;351:394-8.

6 Zelante L, Gasparini P, Estivill X, et al. Connexin26 mutations associated with the most common form of nonsyndromic neurosensory autosomal recessive deafness (DFNB1) in Mediterraneans. Hum Mol Genet 1997;6: 1605-9.

7 Denoyelle F, Marlin S, Weil D, et al. Clinical features of the prevalent form of childhood deafness, DFNB1, due to a connexin-26 gene defect: implications for genetic counselling. Lancet 1999;359:1298-303.

8 Denoyelle F, Lina-Granade G, Plauchu H, et al. Connexin 26 gene linked to a dominant deafness. Nature 1998;393: 26 gene

9 Scott DA, Kraft ML, Stone EM, Sheffield VC, Smith RJH. Connexins mutations and hearing loss. Nature 1998;391:32.

10 Kelley PM, Harris DJ, Comer BC, et al. Novel mutations in the connexin 26 gene (GJB2) that cause autosomal recessive (DFNB1) hearing loss. Am $\mathcal{F}$ Hum Genet 1998;62:792-9.

11 Dib C, Fauré S, Fizames C, et al. A comprehensive genetic map of the human genome based on 5,264 microsatellites. Nature 1996;380:152-4.
12 Bruzzone R, White TW, Paul DL. Connections with connexins: the molecular basis of direct intercellular signaling. Eur f Biochem 1996;238:1-27.

13 Kumar NM, Gilula NB. The gap junction communication channel. Cell 1996;84:381-8.

14 Kikuchi T, Kimura RS, Paul DL, Adams JC. Gap junctions in the rat cochlea: immunohistochemical and ultrastructural analysis. Anat Embryol 1995;191:101-18.

15 Lautermann J, ten Cate WJ F, Altenhoff P, et al. Expression of the gap-junction connexins 26 and 30 in the rat cochlea. Cell Tissue Res 1998;294:415-20.

16 Xia J, Liu C, Tang B, et al. Mutations in the gene encoding gap junction protein $\beta-3$ associated with autosomal dominant hearing impairment. Nat Genet 1998;20:370-3.

17 Milks LC, Kumar NM, Houghten R, Unwin N, Gilula NB. Topology of the 32-kd liver gap junction protein determined by site-directed antibody localizations. EMBO 7 1998;7:2967-75.

18 Sillén A, Annerén G, Dahl N. A novel mutation (C201R) in the transmembrane domain of connexin 32 in severe X-linked Charcot-Marie-Tooth disease. Hum Mutat 1998; suppl 1:S8-9

19 Richard G, White TW, Smith LE, et al. Functional defects of Cx26 resulting from a heterozygous missense mutation in a family with dominant deaf-mutism and palmoplantar keratoderma. Hum Genet 1998;103:393-9.

20 Maestrini E, Korge BP, Ocana-Sierra J, et al. A missense mutation in connexin26, D66H, causes mutilating keratoderma with sensorineural deafness (Vohwinkel's syndrome) in three unrelated families. Hum Mol Genet. 1999;8:123743. 